\title{
Synthesis and Multipole Plasmon Resonances of Spherical Aluminum Nanoparticles
}

Hua Yu', Peng Zhang², Shaoyong Lu ${ }^{1}$, Shuang Yang ${ }^{1}$, Fei Peng ${ }^{1}$, Wei-Shun Chang ${ }^{3}$, Kun Liü*

${ }^{1}$ State Key Laboratory of Supramolecular Structure and Materials, College of Chemistry, Jilin University, Changchun 130012, P. R. China

2 Department of Thoracic Surgery, First Hospital of Jilin University,

Changchun 130021, P. R. China

${ }^{3}$ Department of Chemistry and Biochemistry, University of Massachusetts

Dartmouth, North Dartmouth, Massachusetts 02747, United States 


\section{Table of Contents}

\section{Experimental Section}

1.1 Materials

1.2 Synthesis of Al NPs

1.3 Ligand exchange of spherical Al NPs with PEO

1.4 Measurement the molar extinction coefficient of Al NPs with different sizes

\section{Characterizations}

\section{FDTD Simulations}

\section{Supplementary Tables and Figures}

Table S1. Summary of the experimental and simulated data for the molar extinction coefficient $(\varepsilon)$ and the peak positions $\left(\lambda_{\text {dipole }}\right)$ of spherical Al NPs with different diameter $(D)$.

Table S2. Summary of extinction cross Sections $C_{\mathrm{ext}}$ for different sizes of $\mathrm{Al}$ and $\mathrm{Ag}$ nanoparticles.

Figure S1. TEM images of Al NPs synthesized with 2.0, 3.0 and $4.0 \mathrm{mM} \mathrm{Ti}\left[\mathrm{OCH}\left(\mathrm{CH}_{3}\right)_{2}\right]_{4}$.

Figure S2. SEM images of $200 \mathrm{~nm} \mathrm{Al} \mathrm{NPs} \mathrm{synthesized} \mathrm{at} 45^{\circ} \mathrm{C}$.

Figure S3. UV-Vis spectra (a) and DLS (b) of Al NPs before and after ligand exchange.

Figure S4. FDTD simulation framework for the ensemble extinction spectra of Al NPs.

Figure S5. UV-Vis spectra of Al NPs with different concentrations.

Figure S6. Plot of extinction peak intensity $(A)$ of dipolar resonance with the concentration of $\mathrm{Al}$ NPs $\left(C_{\mathrm{NP}}\right)$ with different diameter.

Figure S7. The calculated absorption cross sections $\left(C_{\mathrm{abs}}\right)$, scattering cross sections $\left(C_{\mathrm{sca}}\right)$, and extinction cross sections $\left(C_{\text {ext }}\right)$ spectra of Al NPs with $D$ from 25 to $200 \mathrm{~nm}$.

Figure S8. Logarithmic plots of calculated extinction cross sections $\left(C_{\text {abs }}\right)$, scattering cross sections $\left(C_{\text {sca }}\right)$, and absorption cross sections $\left(C_{\text {ext }}\right)$ of the dipole (a), quadrupole (b), and octupole (c) modes with the diameter of $\mathrm{Al}$ nanospheres from 25 to $200 \mathrm{~nm}$.

\section{Reference}




\section{Experimental Section}

\subsection{Materials}

1-methylpyrrolidine (1-MP) (98\%) was purchased from Alfa Aesar. Lithium aluminum hydride $\left(\mathrm{LiAlH}_{4}\right)$ (98\%) was obtained from TCI Shanghai. Titanium (IV) isopropoxide $\left(\mathrm{Ti}\left[\mathrm{OCH}\left(\mathrm{CH}_{3}\right)_{2}\right]_{4}\right)(99 \%)$ was purchased from Amatek Chemical Co., Ltd. (Soochow, China). Styrene (99.0\%) was purchased from Xilong Scientific Co., Ltd. and was purified by passage over a column of basic aluminum oxide (Sinopharm Chemical Reagent Co., Ltd.). Cumyl dithiobenzoate (CDTB) (97\%) was purchased from Chemsoon Co., Ltd. and used as received. Poly(ethylene oxide) (number average molecular weight, $M_{\mathrm{n}}=10 \mathrm{~kg} / \mathrm{mol}$ ) was purchased from Alfa Aesar. Azobisisobutyronitrile (AIBN) (98\%, Aladdin) was recrystallized twice with methanol before use. Tetrahydrofuran (THF) $(99.9 \%)$ and aluminium chloride $\left(\mathrm{AlCl}_{3}\right)(99 \%)$ were purchased from Fisher Scientific. Toluene (99.5\%) and methanol (99.5\%) were purchased from Beijing Chemical Work. Deionized (DI) water $(18.2 \mathrm{M} \Omega * \mathrm{~cm})$ was used for all solution preparations.

\subsection{Synthesis of Al NPs}

$\mathrm{H}_{3} \mathrm{Al}(1-\mathrm{MP})$ and cumyl dithiobenzoate-terminated polystyrene (CDTB-PS) $(4.5 \mathrm{~kg} / \mathrm{mol})$ was synthesized according to previously reported protocols. ${ }^{1}$ Toluene, THF and 1-MP was dried prior to use with sodium-potassium alloy (potassium $78 \mathrm{wt} \%$, sodium $22 \mathrm{wt.} \%$ ).

All the syntheses and purification were performed under an oxygen and water-free atmosphere in a glove box. In a typical synthesis of Al NPs with an average longest axis length, of $129.2 \pm 10.7$ $\mathrm{nm}$ as shown in (Figure 1d), a mixture of THF $(4.365 \mathrm{ml})$ and CDTB-PS solution $(20 \mathrm{mM}, 75 \mu \mathrm{l}$ in THF) were heated to $60{ }^{\circ} \mathrm{C}$. Under vigorous stirring (500 r.p.m.), $\mathrm{H}_{3} \mathrm{Al}(1-\mathrm{MP})$ solution ( $0.50 \mathrm{M}$, $500 \mu \mathrm{l}$ in toluene) was injected to the mixture, immediately followed by adding $\operatorname{Ti}\left[\mathrm{OCH}\left(\mathrm{CH}_{3}\right)_{2}\right]_{4}$ solution $\left(100 \mathrm{mM}, 60 \mu \mathrm{l}\right.$ in toluene) to catalyze the decomposition of $\mathrm{H}_{3} \mathrm{Al}(1-\mathrm{MP})$. The reaction solution was stirred for 2 minutes after the addition of $\operatorname{Ti}\left[\mathrm{OCH}\left(\mathrm{CH}_{3}\right)_{2}\right]_{4}$ and then it was incubated at $60{ }^{\circ} \mathrm{C}$ for 3 hours. The solution was cooled down to room temperature and purified by two cycles of centrifugation at 12,000 r.p.m. for 10 min with THF.

The shape of Al NPs was tuned through adjusting the concentration of Ti[OCH( $\left.\left(\mathrm{CH}_{3}\right)_{2}\right]_{4}$ added into the reaction solution with a constant reaction temperature at $60{ }^{\circ} \mathrm{C}: 0.20 \mathrm{mM}(\operatorname{rod} \&$ right bipyramids), $0.40 \mathrm{mM}$ (cube \& right bipyramids), $0.80 \mathrm{mM}$ (truncated-cube \& truncated-right bipyramids) and $1.20 \mathrm{mM}$ (quasi-sphere). The total volume of reaction solutions was kept equally as $5.0 \mathrm{ml}$ by adjusting the volume of THF solvent.

The size of spherical Al NPs was tuned through adjusting the reaction temperature with a constant concentration of $\mathrm{Ti}\left[\mathrm{OCH}\left(\mathrm{CH}_{3}\right)_{2}\right]_{4}(1.20 \mathrm{mM}): 45^{\circ} \mathrm{C}$ (average diameter, $D: 213.1 \pm 15.6$ $\mathrm{nm}), 50^{\circ} \mathrm{C}(D: 180.9 \pm 14.2 \mathrm{~nm}), 55^{\circ} \mathrm{C}(D: 150.1 \pm 12.5 \mathrm{~nm}), 60^{\circ} \mathrm{C}(D: 136.2 \pm 11.9 \mathrm{~nm}), 65^{\circ} \mathrm{C}$ $(D: 120.9 \pm 10.5 \mathrm{~nm}), 70{ }^{\circ} \mathrm{C}(D: 91.6 \pm 10.7 \mathrm{~nm})$, and $80^{\circ} \mathrm{C}(D: 84.4 \pm 8.4 \mathrm{~nm})$.

\subsection{Ligand exchange of spherical Al NPs with PEO}


The fresh prepared Al NPs were stored in the THF solution under ambient condition. After purification, $200 \mathrm{ul} \mathrm{THF}$ solution of spherical Al NPs in THF was added into $800 \mathrm{ul}$ THF solution of PEO $(10 \mathrm{mg} / \mathrm{ml}, 10 \mathrm{~kg} / \mathrm{mol})$. The mixture was ultrasonicated for 5 minutes and incubated at room temperature overnight. The Al NP@PEO solution was then purified by centrifugation at 10,000 r.p.m. for $10 \mathrm{~min}$ and redispersed into deionized water.

\subsection{Measurement the molar extinction coefficient of Al NPs with different sizes}

The molar extinction coefficient of Al NPs was experimentally determined according to Lambert-Beer law, $A=\varepsilon b C_{\mathrm{NP}}$, where $A$ is the extinction peak intensity of dipolar resonance, $b$ is the light path length $(1.0 \mathrm{~mm})$, and $C_{\mathrm{NP}}$ is the molar concentration of $\mathrm{Al}$ Nanospheres. The molar extinction coefficient were obtained from the slope of the linear region of the absorbanceconcentration curve based on the extinction spectra of freshly prepared DI-water solutions of PEO covered Al NPs with five different concentrations (Figure S3). These aqueous solutions (500 ul) were then mixed with a concentrated $\mathrm{HCl}$ solution $(50 \mathrm{ul}, 11 \mathrm{M})$ and incubated over night to dissolve all the $\mathrm{Al} \mathrm{NPs}$ to $\mathrm{Al}^{3+}$ ions. The concentration of $\mathrm{Al}^{3+}$ ions was detected by inductively coupled plasma atomic emission spectroscopy measurement to give the mass concentration of $\mathrm{Al} \mathrm{NPs}\left(C_{\mathrm{m}}\right)$ in the solution.

The $C_{\mathrm{NP}}$ is calculated as $\quad C_{\mathrm{NP}}=\frac{6 C_{\mathrm{m}}}{\pi \rho D^{3} N_{\mathrm{A}}}$

where $\rho$ is the density of bulk $\mathrm{Al}\left(2.7 \mathrm{~g} / \mathrm{cm}^{3}\right), N_{\mathrm{A}}$ is Avogadro's number.

\section{Characterizations}

SEM imaging was obtained with a Hitachi SU8020 at $3 \mathrm{kV}$. TEM imaging were carried out with Hitachi H-800. The synthesized nanoparticles were dispersed in THF and dropped on a carboncoated 300 mesh TEM grid under ambient condition. Powder X-Ray diffraction (PXRD) measurements of Al NPs drop-coated onto glass substrates were carried out on an Empyrean (PANalytical B. V.) operating at a voltage of $40 \mathrm{kV}$. The UV-Vis extinction spectra of the Al NPs THF solutions in $1.0 \mathrm{~mm}$ quartz cells were recorded using a Lambda 950 (PerkinElmer) Spectrometer from 300 to $1000 \mathrm{~nm}$. The UV-Vis extinction spectra of the spherical Al NPs which ligand exchanged with PEO aqueous solutions were recorded using a Lambda 950 (PerkinElmer) Spectrometer in $1.0 \mathrm{~mm}$ quartz cells from 190 to $1000 \mathrm{~nm}$. Dynamic light scattering (DLS) experiments were performed using a Malvern Instruments Nano ZS Zetasizer at $25{ }^{\circ} \mathrm{C}$. The concentration of $\mathrm{Al}^{3+}$ ions was detected by inductively coupled plasma atomic emission spectroscopy (ICP-AES, Agilent 725).

\section{FDTD Simulations}


FDTD simulations were carried out using the commercial software FDTD Solutions (Lumerical). The total-field scattered-field (TFSF) sources that surrounded the structure were chosen to be modeled with wavelength in the range of 190 to $1000 \mathrm{~nm}$ (aqueous solution), and an analysis group using box power monitors was selected to monitor the cross sections. Dielectric functions in the simulations were formulated using the Palik data for $\mathrm{Al}$ and $\mathrm{Al}_{2} \mathrm{O}_{3}$, Johnson and Christy data for $\mathrm{Au}$ and $\mathrm{CRC}$ data for $\mathrm{Ag}$. Water with a refractive index of 1.33 was used as surrounding environment for all the simulations. Mesh size for the simulations was set at $1.0 \mathrm{~nm}$. All the simulations were carried out with $3 \mathrm{~nm} \mathrm{Al}_{2} \mathrm{O}_{3}$ oxidation layer.

\section{Supplementary Tables and Figures}

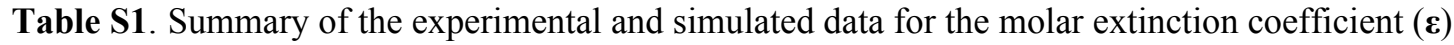
of spherical Al NPs with different diameter $(D)$ at the position of $\lambda_{\text {dipole }}$.

\begin{tabular}{ccc|ccc}
\hline \multicolumn{3}{c|}{ Experimental data } & \multicolumn{3}{c}{ Simulated data } \\
\hline$D(\mathrm{~nm})$ & $\lambda_{\text {dipole }}(\mathrm{nm})$ & $\boldsymbol{\varepsilon}\left(10^{11} \mathrm{~cm}^{-1} \mathrm{M}^{-1}\right)$ & $D(\mathrm{~nm})$ & $\lambda_{\text {dipole }}(\mathrm{nm})$ & $\boldsymbol{\varepsilon}\left(10^{11} \mathrm{~cm}^{-1} \mathrm{M}^{-1}\right)$ \\
\hline 84 & 355 & 0.313 & 50 & 256 & 0.065 \\
\hline 90 & 363 & 0.220 & 75 & 320 & 0.31 \\
\hline 120 & 442 & 1.03 & 100 & 393 & 0.56 \\
\hline 150 & 557 & 1.22 & 125 & 470 & 0.86 \\
\hline 180 & 587 & 2.67 & 150 & 552 & 1.20 \\
\hline 200 & 743 & 2.83 & 175 & 636 & 2.02 \\
\hline \multicolumn{2}{r}{} & & 200 & 745 & 2.55 \\
\hline
\end{tabular}

Table S2. Summary of extinction cross sections $C_{\text {ext }}$ for different sizes of $\mathrm{Al}$ and $\mathrm{Ag}$ nanoparticles.

\begin{tabular}{cccc|cc}
\hline \multicolumn{5}{c|}{ Al (this work) } & \multicolumn{2}{c}{ Ag (ref. 2) } \\
\hline$D(\mathrm{~nm})$ & $\begin{array}{l}C_{\text {ext-dipole }} \\
\left(10^{-11} \mathrm{~cm}^{2}\right)\end{array}$ & $\begin{array}{l}C_{\text {ext-quadrupole }} \\
\left(10^{-11} \mathrm{~cm}^{2}\right)\end{array}$ & $\begin{array}{l}C_{\text {ext-octupole }} \\
\left(10^{-11} \mathrm{~cm}^{2}\right)\end{array}$ & $D(\mathrm{~nm})$ & $\begin{array}{l}C_{\text {ext-dipole }} \\
\left(10^{-11} \mathrm{~cm}^{2}\right)\end{array}$ \\
\hline 25 & 2.5 & & & 29 & 3.13 \\
\hline 50 & 12.0 & & 52 & 17.43 \\
\hline 75 & 21.5 & 23.0 & & 76 & 34.91 \\
\hline 100 & 32.9 & 38.3 & 35.5 & 105 & 59.62 \\
\hline 125 & 45.8 & 53.9 & 56.0 & 120 & 77.24 \\
\hline 150 & 60.6 & 71.0 & 77.1 & 136 & 95.43 \\
\hline 175 & 77.4 & 90.0 & 78.9 & \multicolumn{2}{c}{} \\
\hline 200 & 97.4 & 110.0 & 121.5 & & \\
\hline
\end{tabular}



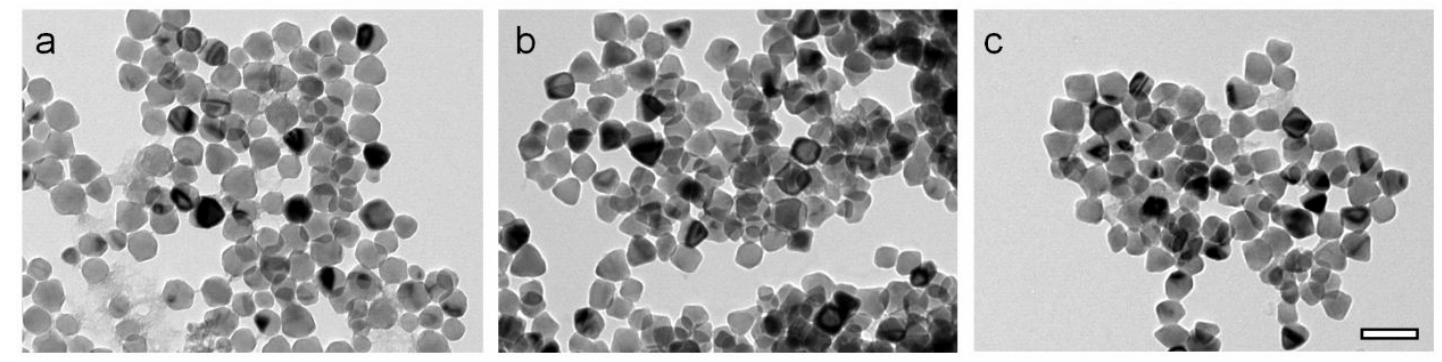

Figure S1. (a-c) TEM images of Al NPs synthesized with 2.0, 3.0, and $4.0 \mathrm{mM} \mathrm{Ti}\left[\mathrm{OCH}\left(\mathrm{CH}_{3}\right)_{2}\right]_{4}$, respectively. Scale bar: $200 \mathrm{~nm}$.
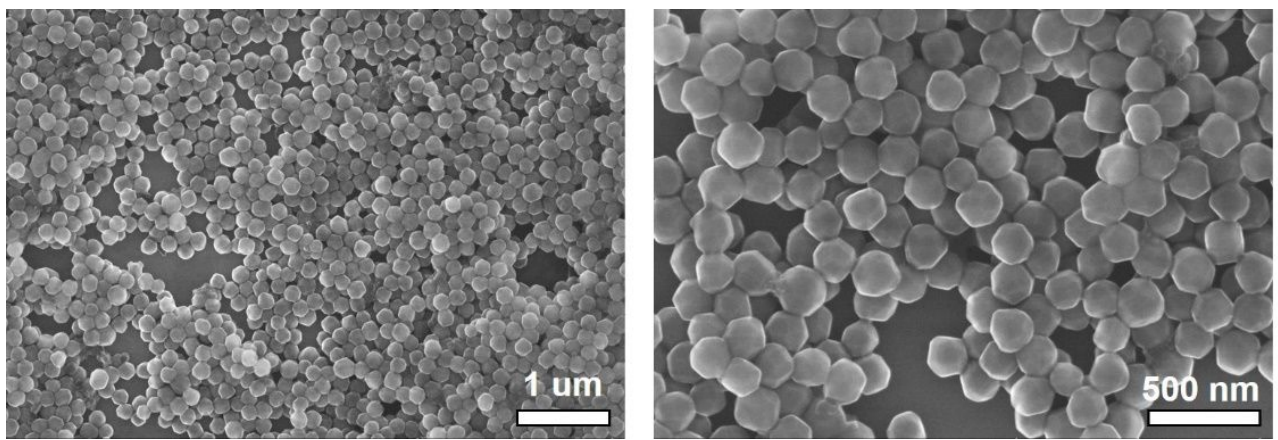

Figure S2. SEM images of $200 \mathrm{~nm} \mathrm{Al} \mathrm{NPs} \mathrm{synthesized} \mathrm{at} 45^{\circ} \mathrm{C}$.
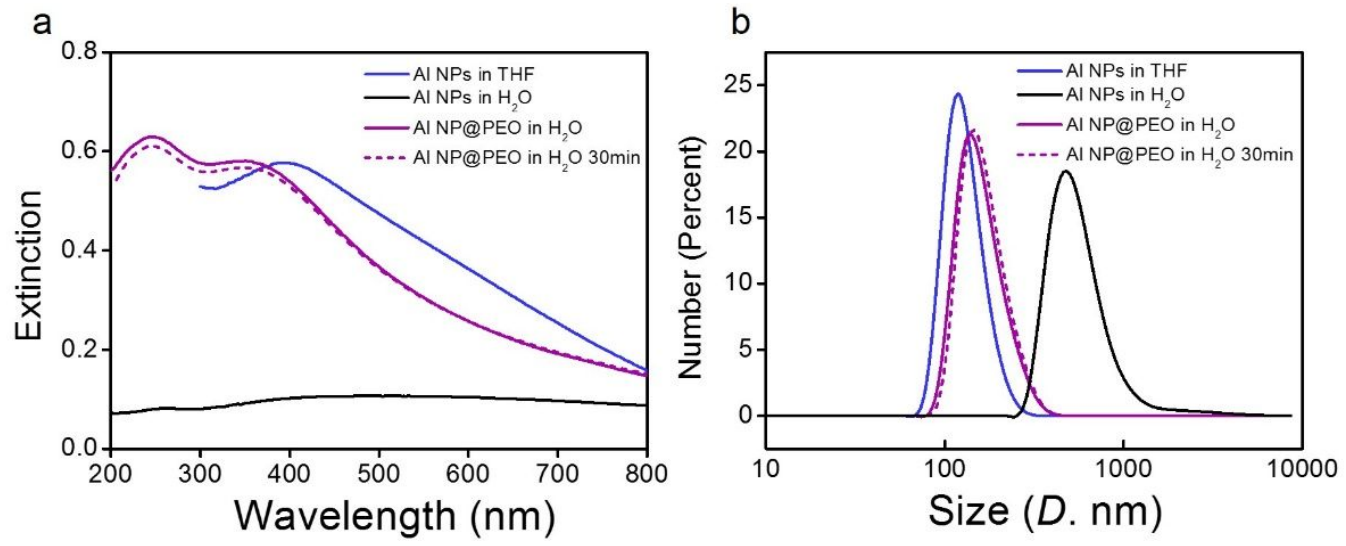

Figure S3. UV-Vis spectra (a) and DLS (b) of $84 \mathrm{~nm} \mathrm{Al} \mathrm{NPs} \mathrm{in} \mathrm{THF} \mathrm{(blue),} \mathrm{Al} \mathrm{NPs} \mathrm{in} \mathrm{H}_{2} \mathrm{O}$ (black), Al NP@PEO in $\mathrm{H}_{2} \mathrm{O}$ (purple), and Al NP@PEO in $\mathrm{H}_{2} \mathrm{O}$ after 30 min (dash), respectively. 
a

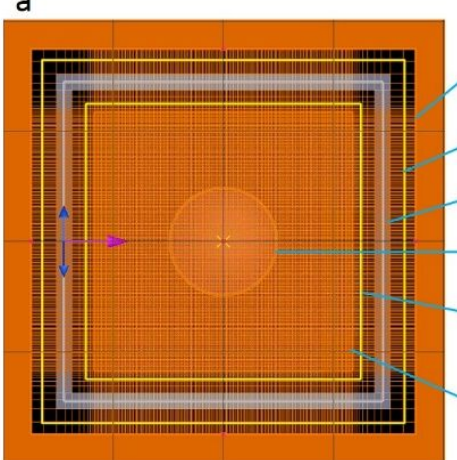

b

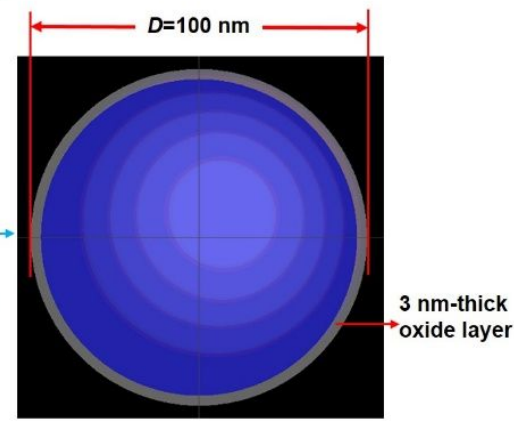

Figure S4. FDTD simulation framework for the ensemble extinction spectra of Al NPs.
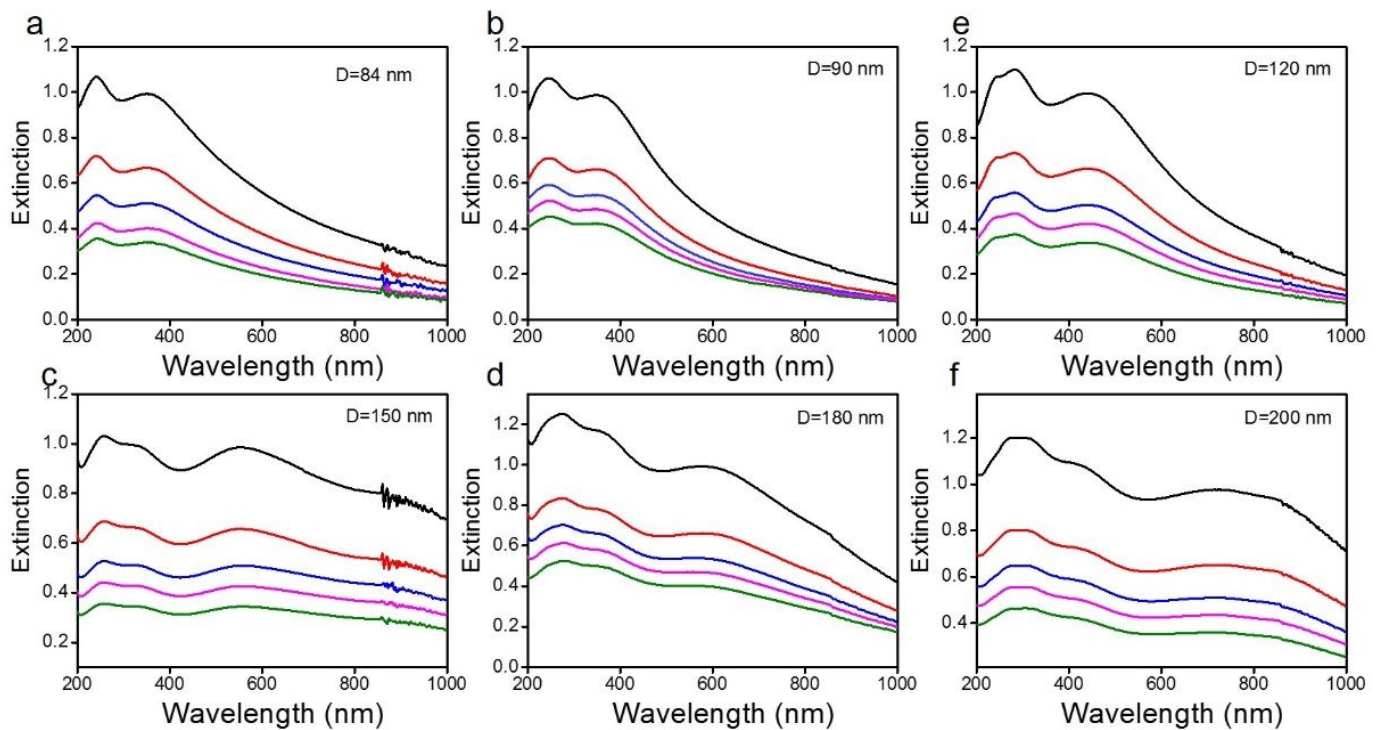

Figure S5. (a-f) UV-Vis spectra of Al NPs with different concentrations.

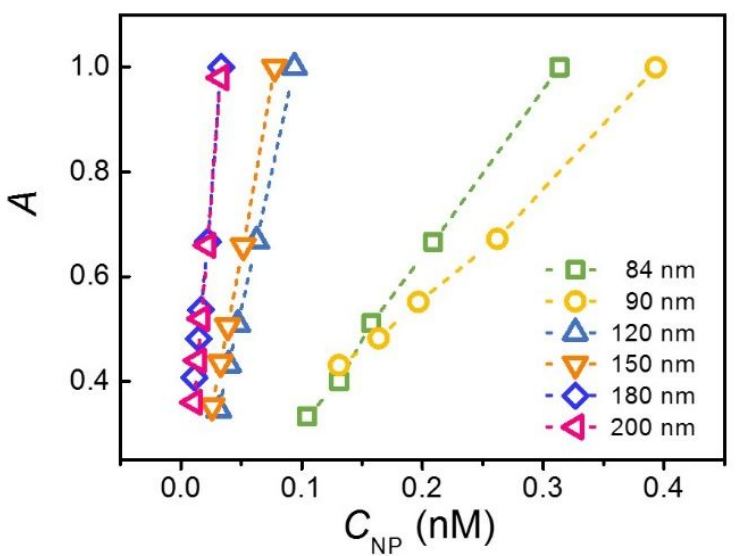

Figure S6. Plot of extinction peak intensity $(A)$ of dipolar resonance with the concentration of $\mathrm{Al}$ NPs $\left(C_{\mathrm{NP}}\right)$ with different sizes. 

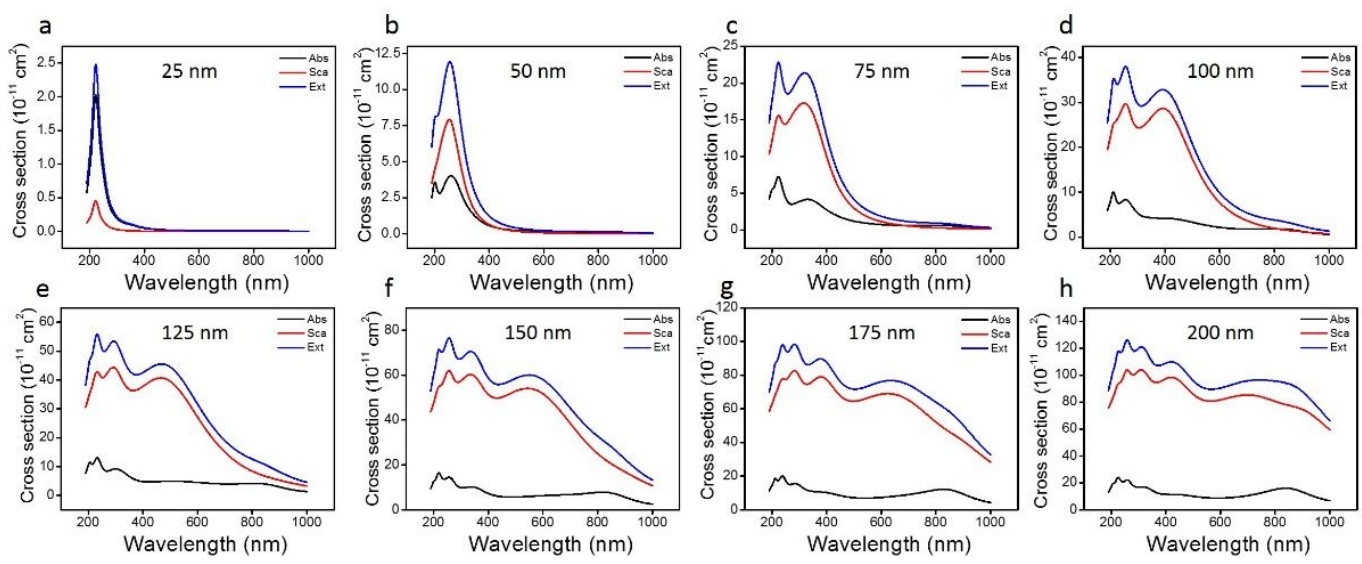

Figure $\mathbf{S} 7$. The calculated absorption cross sections $\left(C_{\mathrm{abs}}\right)$, scattering cross sections $\left(C_{\mathrm{sca}}\right)$, and extinction cross sections $\left(C_{\text {ext }}\right)$ spectra of Al NPs with $D$ from 25 to $200 \mathrm{~nm}$.
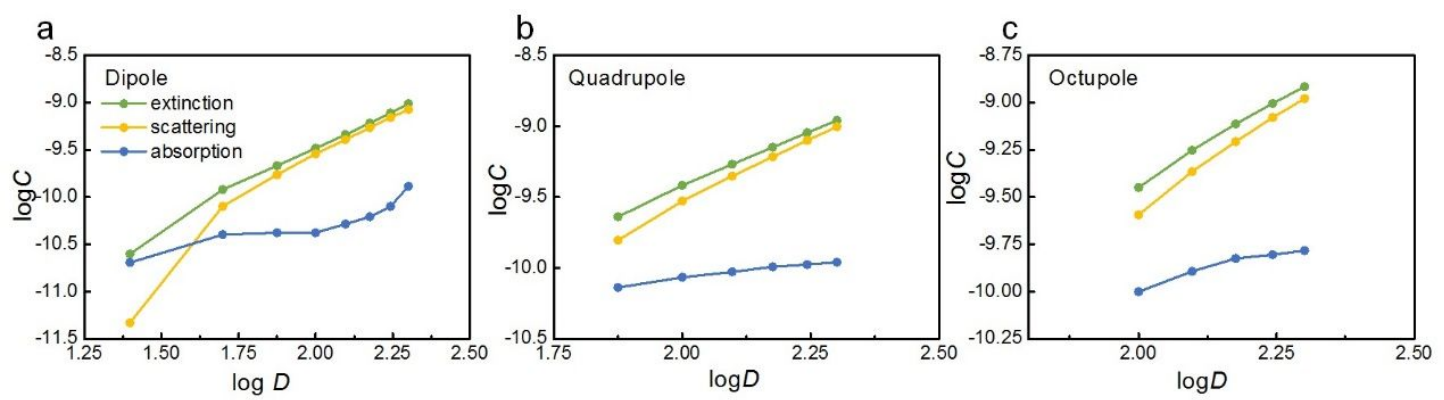

Figure S8. Logarithmic plots of calculated extinction cross sections $\left(C_{\text {abs }}\right)$, scattering cross sections $\left(C_{\text {sca }}\right)$, and absorption cross sections $\left(C_{\text {ext }}\right)$ of the dipole (a), quadrupole (b), and octupole (c) modes with the diameter of $\mathrm{Al}$ nanospheres from 25 to $200 \mathrm{~nm}$.

\section{References}

1. Lu, S.; Yu, H.; Gottheim, S.; Gao, H.; DeSantis, C. J.; Clark, B. D.; Yang, J.; Jacobson, C. R.; Lu, Z.; Nordlander, P.; Halas, N. J.; Liu, K. Polymer-Directed Growth of Plasmonic Aluminum Nanocrystals. J. Am. Chem. Soc. 2018, 140, 15412-15418.

2. Evanoff, D. D.; Chumanov, G. Size-Controlled Synthesis of Nanoparticles. 2. Measurement of Extinction, Scattering, and Absorption Cross Sections. J. Phys. Chem. B 2004, 108, 1395713962. 